Revue d'histoire de l'Amérique française

REYUE D.HISTOIRE DE L'AMÉRIQUE FRANÇAISE

\title{
PELLENS, Karl, Siegfried QUANDT et Hans SÜSSMUTH, dir., Geschichtskultur - Geschichtsdidektik : Internationale \\ Bibliographie. Paderborn, Ferdinand Schoningh, 1984. 378 p. (Geschichte, politik: Studien zur Didektik; Band 3).
}

\section{Christian Laville}

Volume 39, numéro 3, hiver 1986

URI : https://id.erudit.org/iderudit/304387ar

DOI : https://doi.org/10.7202/304387ar

Aller au sommaire du numéro

Éditeur(s)

Institut d'histoire de l'Amérique française

ISSN

0035-2357 (imprimé)

1492-1383 (numérique)

Découvrir la revue

Citer ce compte rendu

Laville, C. (1986). Compte rendu de [PELLENS, Karl, Siegfried QUANDT et Hans SÜSSMUTH, dir., Geschichtskultur - Geschichtsdidektik: Internationale Bibliographie. Paderborn, Ferdinand Schoningh, 1984. 378 p. (Geschichte, politik : Studien zur Didektik ; Band 3).] Revue d'histoire de l'Amérique française, 39(3), 439-439. https://doi.org/10.7202/304387ar d'utilisation que vous pouvez consulter en ligne. 


\section{NOTES BIBLIOGRAPHIQUES}

PELLENS, Karl, Siegfried QUANDT et Hans SÜSSMUTH, dir., Geschichtskultur - Geschichtsdidektik: Internationale Bibliographie. Paderborn, Ferdinand Schoningh, 1984. 378 p. (Geschichte, politik: Studien zur Didektik; Band 3).

Cette bibliographie internationale de didactique de l'histoire et de culture historique est sûrement la plus vaste et la plus complète jamais publiée au confluent des champs du savoir qui constituent son titre. Elle comprend des bibliographies nationales pour quatorze pays: neuf pays d'Europe occidentale, trois d'Europe de l'Est, les États-Unis, la Turquie.

Chacune des bibliographies nationales commence par présenter, en quelques pages, la place que l'histoire et l'enseignement de l'histoire tiennent dans le pays en question et décrit habituellement la situation locale de la didactique. Suivent les entrées bibliographiques, d'une cinquantaine pour certains pays à plus de quatre cents pour d'autres, reproduites dans la langue d'origine. Les entrées sont distribuées selon un canevas commun, bien que plus ou moins respecté par les collaborateurs nationaux (et même pas du tout dans un cas). On y trouve des rubriques sur les instruments de travail, les ouvrages généraux, les revues et les périodiques, d'autres sur les principes et l'histoire de la didactique, sur la recherche, sur l'histoire à l'école et hors de l'école, etc. En tout une dizaine de rubriques, la plupart décomposées en sous-rubriques.

L'ouvrage s'ouvre sur deux essais, l'un examinant diverses conceptions de la didactique de l'histoire, l'autre réfléchissant à la dimension internationale de cette discipline. Il se clot sur les présentations des principales revues qui s'intéressent à l'enseignement de l'histoire en Europe et en Amérique du Nord. Ces textes sont en allemand et, sauf le dernier, risquent d'être d'accès moins facile que les bibliographies pour ceux qui ne sont pas familiers de la langue.

Cette bibliographie, dont c'est la première édition, n'est pas sans quelques faiblesses: les concepts qui la portent, culture historique et didactique de l'histoire, restent flous ou diversement compris; ses rubriques ne sont pas toujours bien ajustées ni entendues de la même manière d'un collaborateur à l'autre; elle est très inégalement sélective; trop de pays en sont absents, dont certains ont pourtant une production importante dans le domaine... Mais déjà, dans son état actuel, et vu les besoins et le manque d'instruments de travail, nul doute qu'elle est appelée à rendre des services importants.

Département de didactique

CHRISTIAN LAVILLE Université Laval 